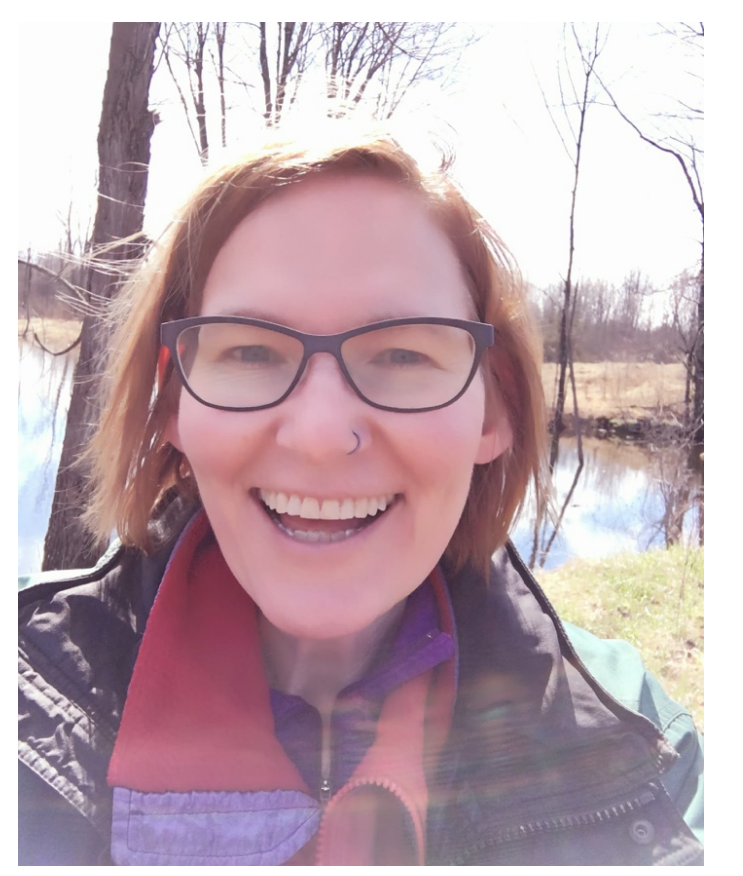

\title{
Western Faculty Profile: Dr. Elizabeth MacDougall-Shackleton
}

\author{
Dora Parkinson ${ }^{1}$ \\ ${ }^{1}$ Faculty of Science, Western University, London, Canada \\ No conflicts of interest declared
}

\section{Background}

I have been teaching here at Western for about fourteen years and for the last ten years Introduction to Biology has been one of the main courses that I teach. Before that, I grew up in Dundas, Ontario near Hamilton, not too far from here. And I did my undergrad degree in biology at Queens, and it was at Queens that I first became interested in pursuing a career in research. I got into research in between third and fourth year, when I realized that I could get paid to hike around outside, climb trees and catch birds, basically doing all these things that I would be doing in my spare time for free. And so I did my Masters Degree at Queens, then went to Princeton to do a Ph.D. - working on birds pretty much the whole time. And when I was in Princeton, I would spend my summers out in California doing field research just outside Yosemite park, living in a tent for around four months of the year. Along the way, I met my husband - he is also a scientist, he is in the psych department here at Western. We came to western about fourteen years ago and here I am now.

\section{What hobbies and Interests do you have?}

Bird watching is obviously one of my main hobbies. I love being outside, hiking around even when I am not doing research. Otherwise, I have got a lot of pets, I have got two big Labrador retrievers, a cat and seven little birds. So I take care of the pets and I spend time with my family - I have two teen-aged kids, and I play piano, jazz piano, and classical piano.

\section{Why did you choose biology?}

Like many people, one of the main reason why I was interested in biology when I first started school was as a route to medical school. And of course, biology is a great major to take if you are interested in issues related to human health. So that's what got me in the door, but once I was taking classes, field courses, and doing research in biology then I realized just how cool it is to be outside and engaging with the natural world. There's a lot of applied problems that we work on: questions related to conservation and populations.

\section{What kind of research have you done and what are you working on now? Where do you see your research ultimately going?}

Some cool findings that we found were that birds were doing better with the parasites from local area than compared to other areas. Really exciting to find, but a disturbing thing to find because ranges of parasites shifting. New parasite-host combinations are going to occur in a changing climate, it's kind of worrisome news in the perspective of conservation. Wildlife populations are pretty well adapted to the parasites they have an evolutionary relationship with, they don't do so well with new parasites. So then we were looking for is there a genetic basis, looking for immune alleles that are locally protective. We haven't found those yet, but that's one of the big areas that we are following up on.

When we think about birds and the ways that they communicate, we know that they have really attractive visual ornaments, lots of birds with fancy plumage and visual displays. Many birds have great songs, so we think of visual and acoustic demonstration. However, the paper that my phD student Joel led, suggested that a lot of information is actually chemically conveyed and the chemical composition of feather wax, which influences the way they smell, actually varies with immune genotype. So if you want to find a mate that is very different from you are at an immune loci, which might be a good thing in terms of producing genetically diverse offspring, then it seems like smelling is one of the best ways to do that. 


\section{What made you choose Western University as opposed to other academic institutions?}

Western has become a really great place for ornithologists - scientists of birds. Since I've been here, we've built the advanced facility for avian research, which is just unparalleled and I have colleagues in Europe, in Asia, in the states and nobody has anything like what we have in terms of working with birds in captivity, semi-natural, or simulating conditions of high altitude flight in the wind tunnel. So yeah the equipment is great. My colleagues are great.

\section{In your opinion, what qualities would make one an excellent researcher?}

Probably number one, you need to love what you're doing. If you don't love your project on day one, if its not an area you already very interested in, it's going to be very challenging to get through the times when your progress starts to stall or this reaction doesn't work or it rains for a month straight. You're in the field if you are very motivated by curiosity about a particular question, then that will help give you the resilience to get through the tough times, because there will always be tough times. Another really important feature of best researchers I know is just the ability to pick yourself up when you have a setback and pull yourself through. So resilience and curiosity are the main ones, being able to get along with people too because more and more of science is collaborative. All the papers you have been looking at are done by me and graduate students and other faculty members at western who have skills that I don't. For example, the organic chemistry of preen wax compounds- the day I got my 50 in organic chem was the happiest day of my life, so that was up to my colleagues who are much more into the biochemistry than I am.

\section{What is the most rewarding part of doing research?}

I love getting new ideas and sitting down with students or my collaborators with a brilliant hypothesis and ask "how do we test that?" There's a beautiful time between when you first conceptualize the idea and when you start setting up the experience and data comes in, where you construct these beautiful pictures in your mind about how it is all going to turn out. Of course, half the time we are actually mistaken and it's exciting being wrong too. For example, I would've thought birds probably can't smell and there's no function contained in their feather preen wax, but it's really exciting when we are wrong too.

\section{What advice do you have to give to students who are looking to do research?}

Keep a really open mind. Approach many people, many potential research supervisors. One great way to get involved in research is to do volunteer work in a lab, but there are people working on research questions that many students haven't even thought about yet, so it's hard to tell which research questions will be exciting for you. But get involved early because there are so many great ways in which people do science.

\section{To Learn more on Dr. MacDougall- Shackleton's lab and research, please visit her website at:}

https://www.uwo.ca/biology/directory/faculty/macdougallshacklet on.html 